\title{
Combined Extracranial-Intracranial Bypass Surgery with Stent-Assisted Coil Embolization for Moyamoya Disease with a Ruptured Wide-Necked Basilar Trunk Aneurysm: A Case Report
}

\author{
Rüptüre Geniş Boyunlu Baziller Trunkus Anervizmaln Moyamoya \\ Hastalığı için Stent Yardımlı Sarmal Embolizasyonuyla Kombine \\ Ekstrakraniyal-Intrakraniyal Bypass Cerrahisi: Bir Olgu Raporu
}

Hanqiang JIANG, Wei NI, Yu LEI, Yanjiang LI, Yuxiang GU

Fudan University, Huashan Hospital, Department of Neurosurgery, Shanghai, China

Corresponding Author: Yuxiang GU / E-mail: guyuxiang1972@126.com

\begin{abstract}
A ruptured wide-necked basilar trunk aneurysm is uncommon in patients with moyamoya disease. The optimal treatment is unclear. We report a safe and beneficial treatment modality for moyamoya disease with aneurysms located in the posterior circulation.

A 37-year-old man presenting with subarachnoid hemorrhage was admitted to our hospital. Emergent cerebral angiography demonstrated moyamoya disease associated with a wide-necked basilar trunk aneurysm. We performed bilateral extracranial-intracranial bypass surgeries prior to stent-assisted coil embolization of the aneurysm after the acute phase. No complication occurred and the patient was discharged with no neurological deficit. Follow-up digital subtraction angiography (DSA) performed 6 months after the surgery showed that all the anastomosises were patent and bilateral collateral vascular compensation was fully established with no recanalization of the basilar trunk aneurysm post embolization.We also found that high-flow bypass did not contribute to cerebral revascularization as imagined despite the good patency.

Combined extracranial-intracranial bypass surgery with endovascular treatment proved to be an efficient therapeutic modality for moyamoya disease with aneurysms located in the posterior circulation. High-flow bypass surgery was not essential due to the inefficiency and the high risk of postoperative cerebral hyperperfusion syndrome.
\end{abstract}

KEYWORDS: Extracranial-intracranial bypass, Coil embolization, Moyamoya disease, Basilar trunk aneurysm

öz

Moyamoya hastalıkıı kişilerde rüptüre geniş boyunlu baziller trunkus anevrizması nadirdir. Optimum tedavi açık değildir. Posterior dolaşımda anevrizmalar bulunan moyamoya hastalığı için güvenli ve faydalı bir tedavi modalitesi bildiriyoruz.

Subaraknoid kanamayla gelen 37 yaşında bir erkek hastaneye yatııldı. Acil serebral anjiyografi geniş boyunlu bir baziller trunkus anevrizmasıyla ilişkili moyamoya hastalığı gösterdi. Akut fazdan sonra anevrizmanın stent yardımlı sarmal embolizasyonu öncesinde bilateral ekstrakraniyalintrakraniyal bypass cerrahisi gerçekleştirdik. Herhangi bir komplikasyon oluşmadı ve hasta nörolojik defisit olmadan taburcu edildi. Cerrahiden 6 ay sonra yapılan takip dijital subtraksiyon anjiyografisi (DSA) anastomozların açık olduğunu ve embolizasyondan sonra baziller trunkus anevrizmasının rekanalizasyonu olmadan bilateral, kollateral vasküler dengeleyici dolaşımın tam olarak tekrar oluştuğunu gösterdi. Ayrıca yüksek akışlı bypass işleminin, iyi açıklığa rağmen serebral revaskülarizasyona tahmin edildiği kadar katkıda bulunmadığını izlendi.

Endovasküler tedaviyle kombine ekstrakraniyal-intrakraniyal bypass cerrahisi, posterior dolaşımda anevrizmalar bulunan moyamoya hastalığı için etkin bir terapötik modalite oldu. Yüksek akışlı bypass cerrahisi, etkin olmaması ve yüksek postoperatif serebral hiperperfüzyon sendromu riski nedeniyle şart değildir.

ANAHTAR SÖZCÜKLER: Ekstrakraniyal-intrakraniyal bypass, Sarmal embolizasyonu, Moyamoya hastalığı, Baziller trunkus anevrizması

\section{INTRODUCTION}

Moyamoya disease (MMD) is an idiopathic cerebrovascular disease characterized by progressive stenosis or occlusion of the terminal portion of the bilateral internal carotid artery (ICA) and the formation of abnormal collateral networks at the base of the brain (8). In recent years, MMD with intracranial aneurysm has been recognized more frequently, especially in patients with a hemorrhagic type. Aneurysms located in the posterior circulation have been estimated to occur in approximately $50-60 \%$ of cases with MMD, of which the 
basilar tip aneurysm was the most common and basilar trunk aneurysm was very rare (3). Moreover, either endovascular treatment or cerebral revascularization was chosen as a surgical strategy for such patients. Combined surgical revascularization with endovascular treatment has never been reported before. In this article, we describe a rare case of MMD with a ruptured wide-necked basilar trunk aneurysm, for which combined extracranial-intracranial bypass surgery with stent-assisted coil embolization was applied for the first time.

The study was approved by ethics committee of Huashan Hospital, Fudan University. Written informed consent was obtained from the patient.

\section{CASE REPORT}

\section{Medical History and Radiological Examination}

A 37-year-old man presented with sudden onset headache and vomiting one month before admission. Emergent computed tomography (CT) plain scan revealed subarachnoid hemorrhage (Figure 1A). Subsequent cerebral angiography (Figure 1B-H) demonstrated moyamoya disease with a wide- necked basilar trunk aneurysm. Taking into account the high risk of rebleeding or fatal complication after stent-assisted coiling of the aneurysm or surgical revascularization in acute phase, we simply gave medication and the symptoms were obviously relieved after one month. After clinical discussion and sign of informed consent, we took the first attempt to perform combined extracranial-intracranial bypass surgery and stent-assisted coil embolization.

\section{Surgical Procedure and Outcome}

To identify high-flow bypass plus low-flow bypass surgery could further increase collateral blood flow and reduce the stress of posterior circulation compared to low-flow bypass surgery alone, we decided to performed right extracranial artery-radial artery-middle cerebral artery (ECA-RA-MCA) and superficial temporal artery-middle cerebral artery (STA-MCA) bypass surgery and left STA-MCA bypass surgery as contrast. We removed the radial artery for the donor of high-flow surgery and cervical incision for exposing ECA initially (Figure 2B). Next, craniotomy of modified pterional approach was utilized to perform ECA-RA-MCA and STA-MCA bypass surgery (Figure 2A). Three anastomoses were successfully sutured finally, one

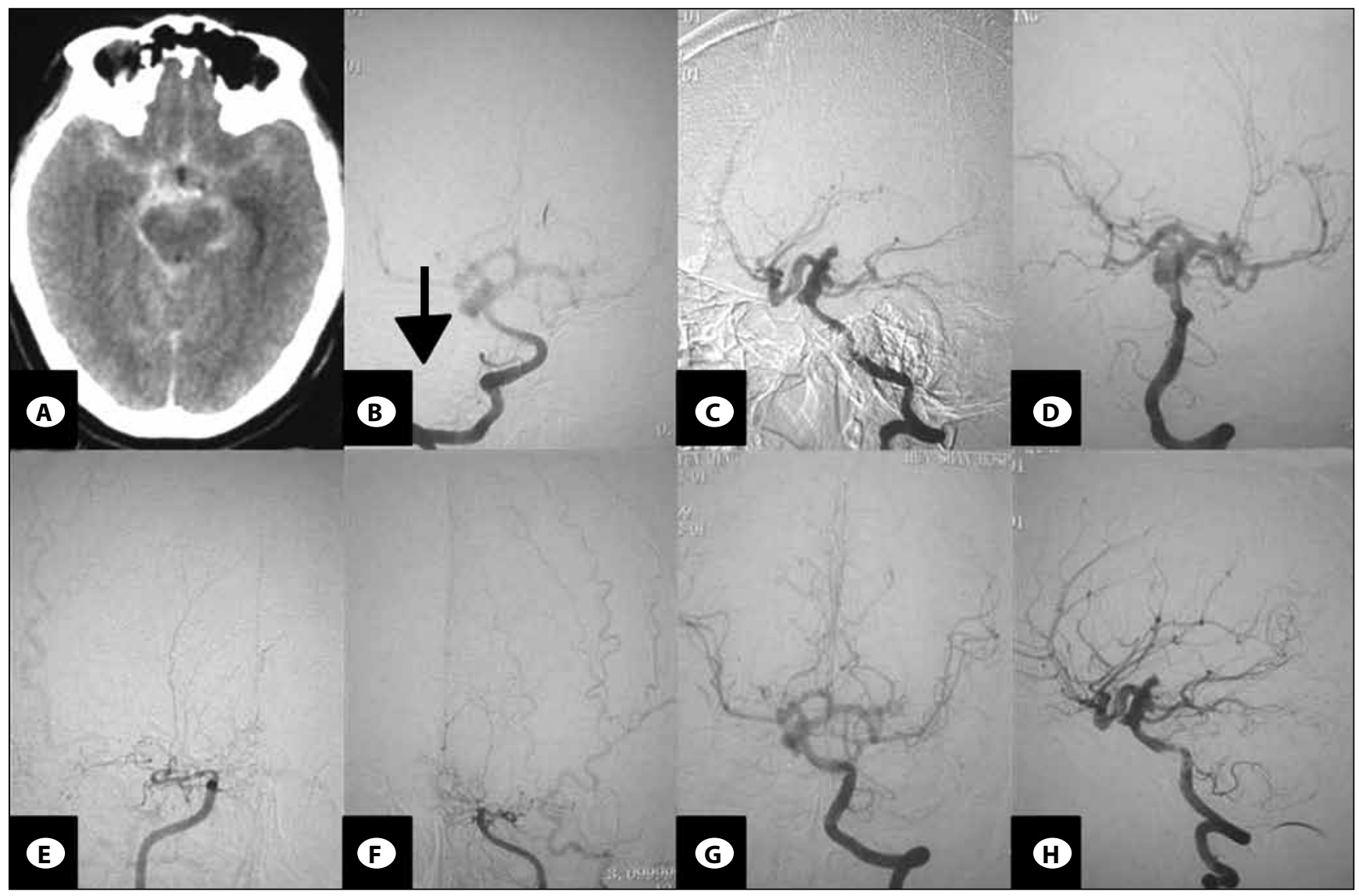

Figure 1: Pre-operative CT scan and 6-vessel cerebral angiogram. A) CT scan revealing subarachnoid hemorrhage (SAH),obvious at ambient cistern and interpeduncular cistern. B-D) Anterior-posterior, lateral and oblique view of right vertebral artery (VA) demonstrating a wide-neck basilar artery trunk aneurysm (arrow) with blood flow compensation from posterior communicating artery (PCOA). E,F) Bilateral internal carotid artery (ICA) angiogram showing moyamoya disease. D,H) Left VA angiogram also displaying the aneurysm and compensation from posterior circulation. 
of which for ECA-RA-MCA and the other two for STA-MCA bypass (Figure $2 \mathrm{C}, \mathrm{D}$ ). Intraoperative ultrasonagraphy was also used to confirm graft patency (Figure 2E). One week after the surgery, left STA-MCA bypass was also performed (Figure 2F). The postoperative period was uneventful and the patient had a good recovery. Two weeks after operation, we repeated DSA and it showed patency of all the anastomoses and effective collateral circulation with no change in size of the basilar trunk aneurysm. (Figure $3 \mathrm{~A}-\mathrm{H}$ ). The shape of the aneurysm was irregular and the size was about $4.0 \mathrm{~mm}$ by $3.0 \mathrm{~mm}$. Therefore we decided to embolize the aneurysm due to the risk of rupture. Oral antiplatelet drugs were primarily administered 3 days before endovascular treatment with a dose of aspirin $300 \mathrm{mg}$ and clopidogrel $75 \mathrm{mg}$. The aneurysm was embolized with 12 coils assisted by a Solitare stent and finally occluded as shown by postprocedural control DSA with no complication (Figure 3I-L). The patient was discharged with no neurological deficit on postprocedural day 3.

\section{Clinical and Radiological Follow Up}

Six months later, the patient was admitted to our hospital again for DSA follow up. He recovered well with no neurological deficit. Follow-up DSA revealed patency of the anastomoses and no recanalization of the aneurysm (Figure $4 \mathrm{~A}-\mathrm{H})$. Interestingly, we noticed that the blood flow from collateral ECA-RA-MCA had obviously decreased compared with DSA 2 weeks after bypass surgery.

\section{DISCUSSION}

The reported incidence of MMD with intracranial aneurysm is about $3-15 \%$ (4). Occasionally, cerebral hemorrhage was caused by the rupture of the aneurysm in patients with hemorrhagic type MMD. Aneurysms were classified into two varieties according to the characteristic feature and site. One variety was major artery aneurysms located in the circle of Willis. The other variety was peripheral artery aneurysms in the collateral networks. Major artery aneurysms were generally considered to be true aneurysms, which would not disappear if not treated. However, peripheral artery aneurysms were thought to be pseudoaneurysms, which could shrink or disappear with time. As shown in this case, the basilar trunk aneurysm was a true aneurysm, which could be the cause of the SAH. Moreover, $50-60 \%$ of true aneurysms with MMD were found to occur in the posterior circulation (3). The tip of basilar artery was a predilection site for aneurysms in the posterior circulation with MMD, possibly caused by hemodynamic stress from occlusion of bilateral ICA. Posteriorinferior cerebellar artery (PICA), anterior-inferior cerebellar artery (AICA) and posterior cerebellar artery (PCA) aneurysms with $M M D$ have also been reported although they are uncommonly discovered. However, a basilar trunk aneurysm with MMD has never been reported and the treatment remains unknown. We report the original case of a ruptured wide-necked basilar trunk aneurysm with MMD.

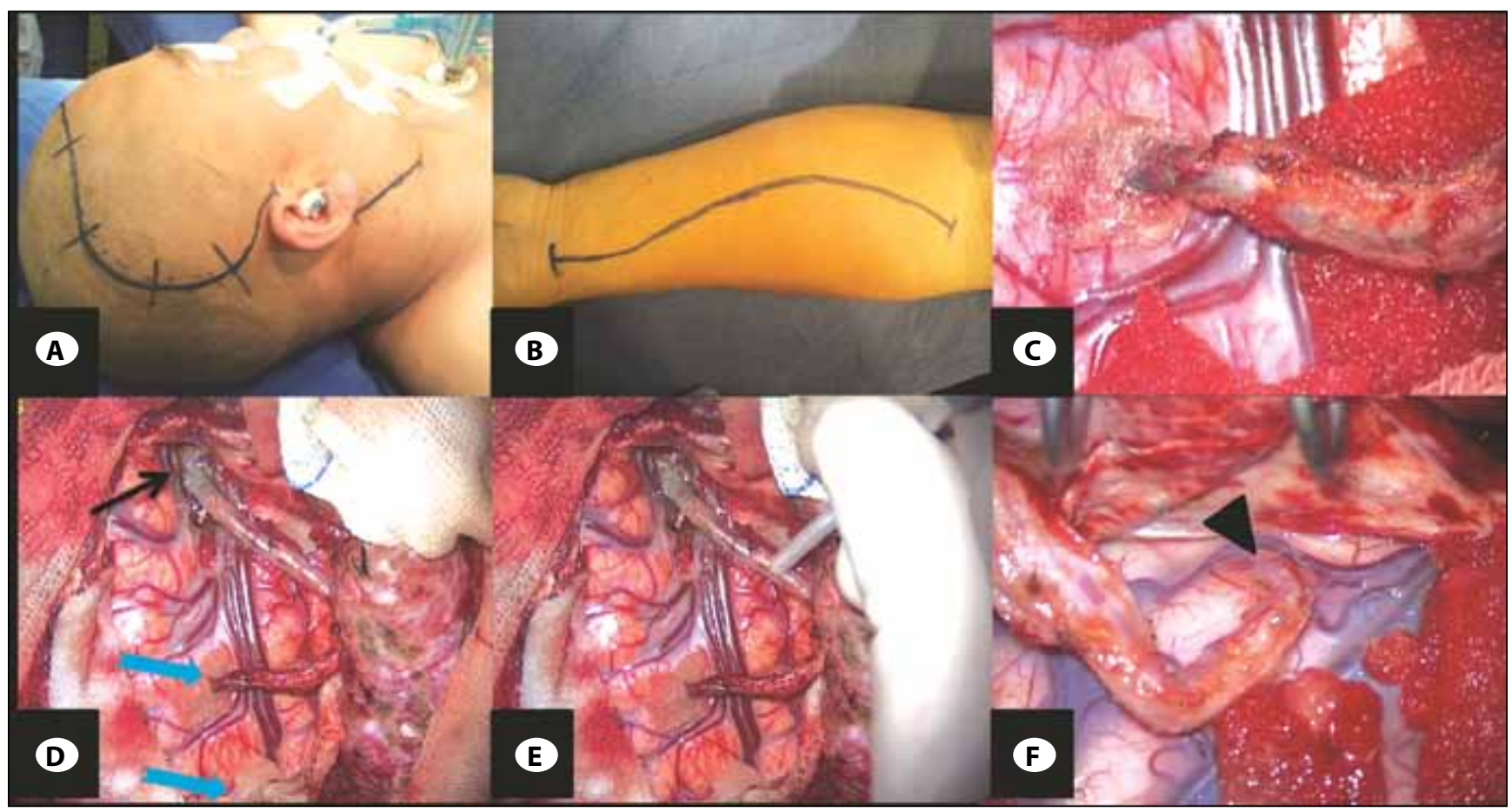

Figure 2: Surgical incision and intraoperative photographs. A) Modified pterional approach and cervical incision for ECA-RA-MCA and STA-MCA bypass surgery. B) Forearm incision for retrieving RA. C) One anastomosis of double STA-MCA bypass. D) ECA-RA-MCA anastomosis (black arrow) and STA-MCA doubles (blue arrow). E) Ultrasonography for confirming the patency of all anastomoses. F) Contralateral hemispheric anastomosis of STA-MCA bypass surgery. 
Aggressive treatment has been advocated for the high risk of rebleeding. Major artery aneurysms with MMD do not spontaneously disappear and should be treated surgically. Therapeutic options include observation, open surgery and endovascular coiling. Most of the reported cases of aneurysms in the posterior circulation with MMD were treated via an endovascular approach because of technical difficulty. In addition, direct surgical clipping carries a risk of breaking transdural anastomosis which was beneficial in patients with MMD. Temporal clipping of the parent vessels or surgical brain damage may also cause irreversible cerebral infarction. Endovascular procedure was suitable for treating the aneuryms with MMD, especially the aneurysms difficult to reach by open surgery and had great advantages over surgical clipping $(5,7)$. Therefore most aneurysms with MMD were treated by endovascular coiling, despite the fact that

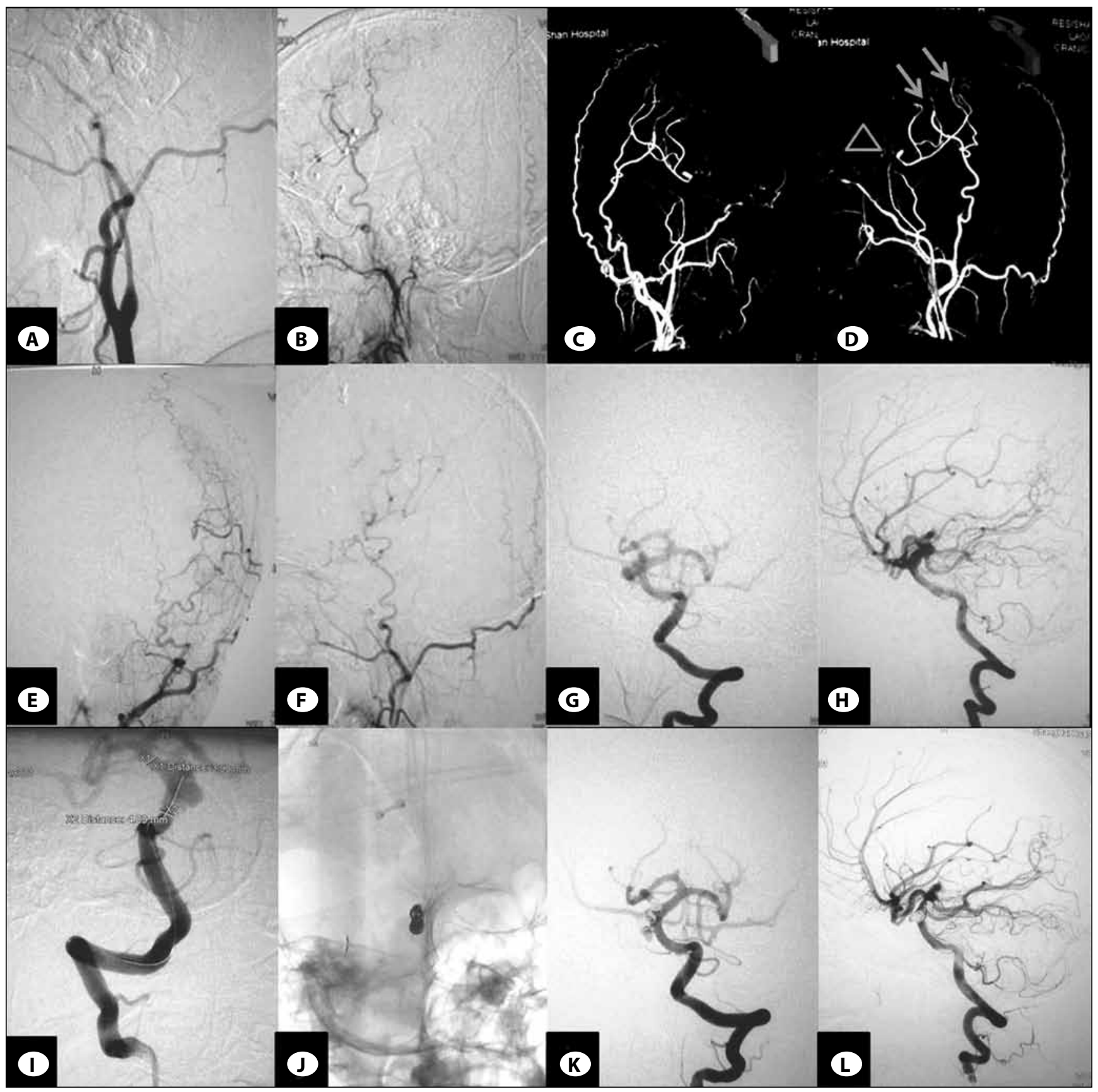

Figure 3: 2-week cerebral angiography follow up and subsequent stent-assisted coiling of basilar artery trunk aneurysm. A-D) Right ECA angiogram showing patency of both ECA-RA-MCA and STA-MCA anastomoses. D,E) Left ECA angiogram likewise demonstrating patency of STA-MCA anastomosis. G,H) Left VA angiograms revealing the aneurysm did not change after bypass surgery. I-L) Stentassisted coil embolization was performed and post embolization angiogram showing total obliteration of the aneurysm. 
cerebral revascularization had never been used alone before $(1,6)$. However, treating aneurysms may only eradicate the direct cause of rebleeding but does not solve the fundamental problem of revascularizing ischemic hemispheres. Combined extracranial-intracranial bypass surgery and endovascular treatment theoretically eliminates the two important factors contributing to cerebral hemorrhage in patients with MMD and associated with intracranial aneurysms, by increasing cerebral blood flow and occluding aneurysms. In this case, two hemispheres were revascularized one week apart. Furthermore, we made a bold innovation in that high-flow and low-flow bypass surgeries were both performed in the patient to compare efficacy. At 6-month follow up, the patient was very well (modified Rankin Scale, mRS 0) and no rebleeding or ischemic episode occurred. Combined cerebral revascularization and endovascular treatment in this rare case provided a good curative effect indeed.

Whether low-flow bypass surgery is effective for patients with MMD associated with intracranial aneurysms is unknown (9). In theory, high-flow bypass surgery could supply more blood flow to anterior circulation and alleviate hemodynamic stress of the posterior circulation. Afterwards, the incidence of recanalization of the embolized aneurysm would decrease.
However, in our case we found that high-flow bypass surgery did not play a great role in establishing collateral networks, regardless of the fact that the anastomosis was patent at 6-month DSA follow up. Low-flow bypass is possibly enough for cerebral revascularization for patients with MMD. Besides, high-flow bypass surgery could cause fatal cerebral hyperperfusion syndrome, which is hard to monitor. The mechanism remains unclear due to the complexity of the hemodynamics involved. However, extracranial-intracranial bypass surgery did play an important role in patients with MMD and did not end up (2).

\section{CONCLUSION}

We reported a very rare case of MMD with a wide-necked basilar trunk aneurysm. Furthermore, combined cerebral revascularization and endovascular treatment were performed for the first time. In view of appropriate outcome of shortterm follow up, it was suggested that combined endovascular treatment for the aneurysms and cerebral revascularization could be performed for eligible patients. STA-MCA bypass could be sufficient for revascularizing ischemic hemispheres in patients with MMD.

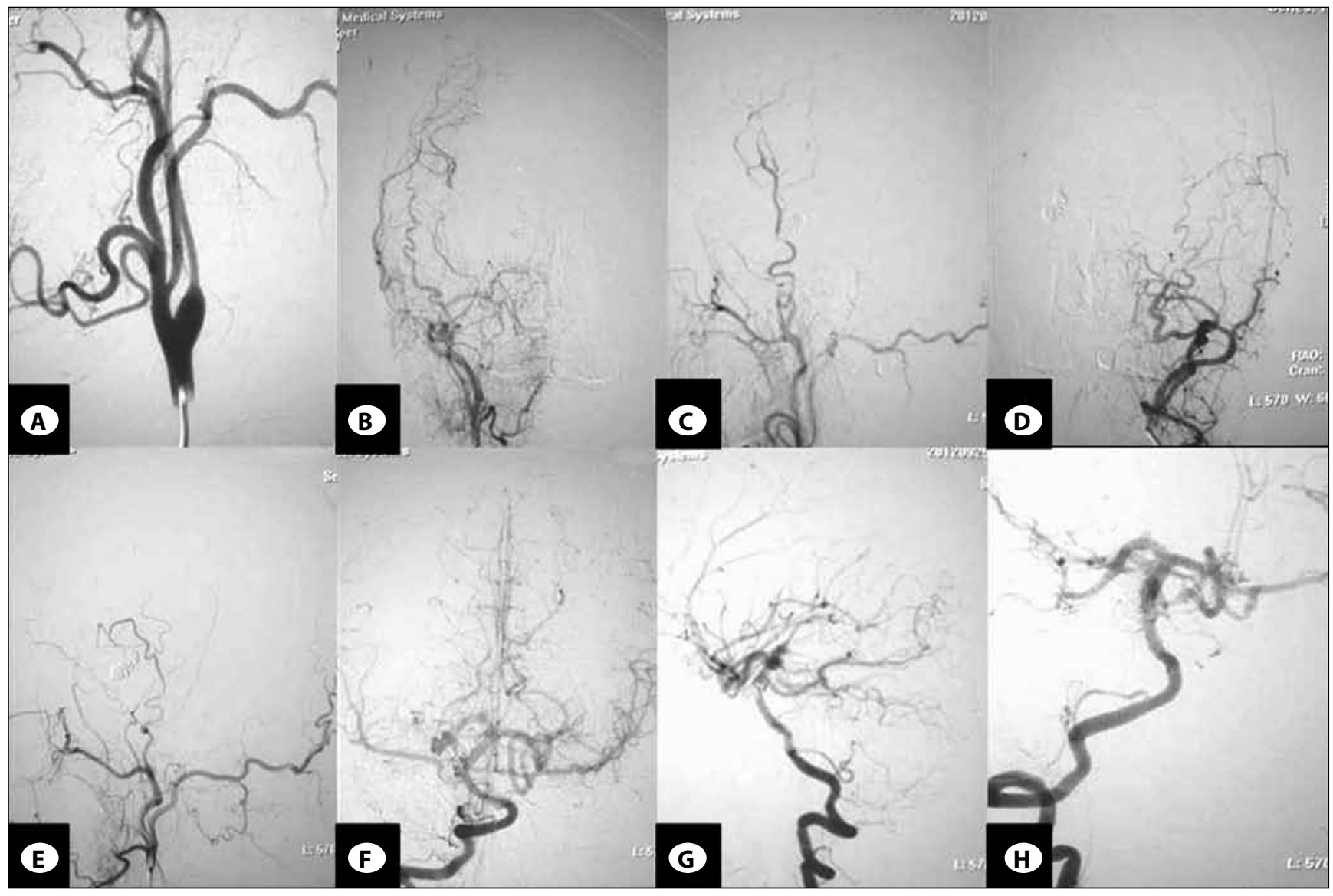

Figure 4: 6-month cerebral angiogram follow-up. A-C) Right ECA angiogram revealing patency of all anastomoses except for reduced blood flow of ECA-RA-MCA bypass and good construction of collateral compensation. D, E) Left ICA angiogram also demonstrated patency of STA-MCA anastomosis. F, G, H) Right VA angiogram showing no recanalization of the embolized aneurysm. 


\section{REFERENCES}

1. Adams HJ, Kassell NF, Wisoff HS, Drake CG: Intracranial saccular aneurysm and moyamoya disease. Stroke 10:174179, 1979

2. Amin-Hanjani S, Barker FN, Charbel FT, Connolly EJ, Morcos JJ, Thompson BG: Extracranial-intracranial bypass for stroke-is this the end of the line or a bump in the road? Neurosurgery 71:557-561, 2012

3. Arai Y, Matsuda K, Isozaki M, Nakajima T, Kikuta K: Ruptured intracranial aneurysms associated with moyamoya disease: Three case reports. Neurol Med Chir (Tokyo) 51:774-776, 2011

4. Kawaguchi S, Sakaki T, Morimoto T, Kakizaki T, Kamada K: Characteristics of intracranial aneurysms associated with moyamoya disease. A review of 111 cases. Acta Neurochir (Wien) 138:1287-1294, 1996

5. Kim SH, Kwon O, Jung CK, Kang H, Oh CW, Han MH, Kim YS, Baik SK: Endovascular treatment of ruptured aneurysms or pseudoaneurysms on the collateral vessels in patients with moyamoya disease. Neurosurgery 65:1000-1004, 2009
6. Ni W, Xu F, Xu B, Liao $Y, G u Y$, Song D: Disappearance of aneurysms associated with moyamoya disease after STAMCA anastomosis with encephaloduro myosynangiosis. J Clin Neurosci 19:485-487, 2012

7. Yu JL, Wang HL, Xu K, Li Y, Luo Q: Endovascular treatment of intracranial aneurysms associated with moyamoya disease or moyamoya syndrome. Interv Neuroradiol 16:240-248, 2010

8. Suzuki J, Takaku A: Cerebrovascular "moyamoya" disease. Disease showing abnormal net-like vessels in base of brain. Arch Neurol 20:288-299, 1969

9. Zhang G, Li J, Chen G, Qin S, Xu G, Gong J, Yang M, Pan L, Zhang $X, M a$ L: Diagnosis and treatment of hemorrhagic moyamoya disease combined with blood flow associated intracranial aneurysm. Cerebrovasc Dis 30:217-218, 2010 